\title{
Screening and Characterization Staphylococcus aureus from Goat Milk
}

\author{
R. Kiruthiga*, S. Leonal Rabins and G.D. Vinoth Kumar \\ Veterinary Assistant Surgeon, Cuddalore, India \\ *Corresponding author
}

Ke y w o r d s
Goat milk,
Staphylococcus
aureus, Toxi-
infection, Antibiotic
resistance, Biofilm,
mecA gene,
Vancomycin

\section{A B S T R A C T}

The study focused on the prevalence of Staphylococcus aureus and resistant strains in goat milk samples. In this study, 100 individual goat raw milk samples were collected. A total of 39 (39\%) isolates were recovered. Strains identified as Staphylococcus aureus were further analysed by the polymerase chain reaction method for detection of the mecA gene. Among the 39 isolates 28 (71.7\%) samples showed positive results for coagulase test, 31 (79.4\%) were of biofilm producers and $21(53.8 \%)$ samples positive for mecA gene. Isolates showed maximum sensitivity as followed; Cefoxitin (83.2\%), Cephalothin (72\%), Kanamycin (76.3\%), Choramphenicol (75.8\%), Erythromycin (71.55\%) and Gentamicin $(70.8 \%) \&$ resistance against Nalidixic acid $(85.8 \%)$, Polymixin B $(82.6 \%)$ and Penicillin G $(70.5 \%)$. Vancomycin (36.7\%) resistant isolates also note worth in present study. Isolates of $S$. aureus revealed the pathogenicity and resistance against the existing antibiotics. Study shows that goat milk also having equal chances of transmission to consumers via contaminated milk consumption. Hence, to improve the quality of milk and to prevent $S$. aureus contamination more hygienic measures should be implemented from point of production to consumption.

\section{Introduction}

Milk and milk products are good source of protein easily accessible in the world. The increasing world population increasing in one side automatically increase the demand for the milk production. Finding the new source to meet the demand is a challenging work. Nowadays consumption of goat milk also increased in order to meet the demand. Goat milk is the most complete food, highly nutritious that it can actually serve as a substitute for a meal. It is also preferred for its low fat content and its capability to neutralize the acids and toxins present in the body (Alferez et al., 2001). Hygienic collection, handling and storage of goat milk globally people recognize the factors involved in the food poisoning. Food borne toxi-infection causes serious health problems to the 
consumers among these, Staphylococcous aureus leading with maximum possibilities and along with emerging of various antibiotic resistant (Golding et al., 2010). Despite all the measures taken in livestock breeding, the incidence of $S$. aureus persists in the environment, in milk, on the animal's body, and also in humans (Harrison et al., 2014).It was shown that animals can spread resistant strains not only in humans but also in raw food materials intended for further processing and for consumption (Trncikova et al., 2010; Loncaric et al., 2013; Shockava and Janstova 2014). S. aureus leading overall cause of health care associated infections globally and as more patients are treated outside the hospital setting is an increasing concern in the community (Stenhem et al., 2010).

In general many anti - Staphylococcal drugs including Tetracycline, Fluoroquinolones, Linezolid and Daptomycin but they quickly loss their therapeutic value due to the ability of the bacterium to develop effective mechanisms to confront these agents (Navratna et al., 2010). Vancomycin considered the last choice for the resistant isolates and many authors are continuously reporting the presence of Vancomycin resistant isolates (Teshome et al., 2016). Moreover MRSA may also resist Vancomycin (Cui et al., 2000) and this clearly shows the threat in community. S. aureus is a wellknown pathogen living in a wide variety of environments (Ciccio et al., 2015). It also has the inherent ability to form biofilms on biotic and abiotic surfaces (Mirani et al., 2013).

Even though many studies have been reported very frequently on $S$. aureus (Kumar et al., 2010., Bharathy et al., 2015) studies from goat milk and public health significances are not included in in our country. Our present study was aimed to screen the samples for the prevalence of $S$. aureus with the main focus on public health significance.

\section{Materials and Methods}

\section{Study population and sampling technique}

A total of 100 individual raw goat milk samples were collected from randomly selected lactating goats (non-descript) in livestock production. Selected goats were kept under traditional management system of rearing. Goat milk samples collected using sterile container. All the chemicals, primers, reagents and culture media used in this study were procured from HiMediaPvt. Ltd Mumbai and PCR mixture procured from Gene Technologies, Chennai. Required equipment and glassware items used in this study were hygienically prepared as per standard procedures.

\section{Primary enrichment and isolation}

One $\mathrm{ml}$ of milk sample diluted with $9 \mathrm{ml}$ of sterile Staphylococcal broth and enriched for $24 \mathrm{hrs}$ at $37^{\circ} \mathrm{C}$. Baired parker agar was used for the selective isolation with $2 \%$ egg yolk emulsion. A loopful of inoculation from enrichment were streaked onto Baired Parker agar and incubated for 24- $48 \mathrm{hrs}$ for the presence selective typical presumptive black colonies surrounded by white halo. Plates with selective colonies were further purified on Muller Hinton agar. After purification, colonies were further streaked onto $5 \%$ sheep blood agar for the assessment of ability of isolates to produce hemolysis.

\section{Primary and secondary identification of Staphylococcus aureus}

Specific colonies initially smeared subjected for the Grams staining and smear shown positive, spherical cells arranged in irregular clusters resembling to bunch of grapes were further subjected for primary and secondary biochemical procedures as per Cowan and Steel's, 1993. Confirmed colonies were 
subjected for Tube coagulase test as per (Bharathy et al., 2015). Details of the tests given in table no. 2 and 3

\section{Preservation and revival of isolates}

A loopful of the isolated organism was added to the sterile DMSO-glycerol broth vials and mixed well in the vortex mixture. The vials were then labeled and stored at $-40^{\circ} \mathrm{C}$. The isolates were revived once in three months. The vials stored at $-40^{\circ} \mathrm{C}$ was thawed and streaked on Nutrient agar and incubated at $37^{\circ} \mathrm{C}$ overnight. The isolated organism was also streaked onto $\mathrm{MH}$ slants in screw capped test tubes and incubated at $37^{\circ} \mathrm{C}$ for 24 hours. Once the growth was obtained the slants were stored at $4^{0} \mathrm{C}$

\section{Detection of $m e c A$ gene by PCR technique}

The reference strain of Staphylococcus aureus was obtained from Institute of Microbial Technology, Chandigar. PCR assay was performed using the DNA amplification instrument Mastercycler gradient (Eppendorf, Germany) to identify MRSA strains. Single colonies were collected from Muller hington agar upon overnight incubation at $37^{\circ} \mathrm{C}$. DNA was extracted as per the manufacturer's instructions given in DNA Extraction Kit (Gene Technologies, Chennai). The mecA specific primer pairs used for the amplification of 533 base pair fragment are Forward, 5'- AAAATCGATGGTAAAG GTTGGC- 3' and Reverse, 5'- AGTTCTGG AGTACCGGTTTGC- 3' (Buhlmann et al., 2008). A $25 \mu 1$ reaction mixture was prepared in $0.2 \mathrm{ml}$ thin walled PCR tubes.

The reaction mixture consists of the following: Template DNA - $5 \mu \mathrm{l}$, Primers $(r f p B)$ - 20 pmol each primer, Master mix $12.5 \mu \mathrm{l}$ and Triple distilled water to $5.5 \mu \mathrm{l}$. Amplification was carried out in an automated thermal cycler (Eppendorf
Mastercycler, Germany) according to the following programme. Initial Denaturation was at $94{ }^{0} \mathrm{C}$ for 3 minutes followed by 30 cycles of Denaturation at $94{ }^{0} \mathrm{C}$ for 30 seconds, Annealing at $60{ }^{0} \mathrm{C}$ for 30 seconds, Extension at $72^{\circ} \mathrm{C}$ for 30 seconds and Final Extension at $72{ }^{0} \mathrm{C}$ for 3 minutes.

\section{Biofilm formation assay (Slime Production} Assay)

Qualitatively, biofilm formation among $S$. aureus isolates were assessed using method as described by (Jyothi et al., 2018) with little modification. Briefly, Brain heart infusion agar supplemented with 5\% sucrose and Congo red $(0.08 \mathrm{~g} / \mathrm{l})$ was prepared and autoclaved. The isolates were inoculated and incubated aerobically for 24 to 48 hours. The ability of the isolates to produce bio-films was indicated by black colonies with a dry crystalline consistency. The results were recorded with positive and negative control.

\section{Antimicrobial susceptibility testing}

All isolates were tested for 16 antimicrobial drugs. List of the antibiotics were used in this study showed in table no. 1. Isolates were sub cultured on nutrient agar plates incubated for $24 \mathrm{hrs}$ at $37^{\circ} \mathrm{C}$. Colonies were picked from the agar plates, and suspended in normal saline $(0.85 \% \mathrm{w} / \mathrm{v})$, and the density of the suspension was adjusted to 0.5 McFarland standard.

The bacterial suspension was spread on the Mueller Hinton agar plates using a sterile swab stick, allowed to dry, and impregnated with antibiotic disk. Plates were incubated at $37^{\circ} \mathrm{C}$ for $24 \mathrm{hrs}$. Diameters of the zones of inhibition were measured and interpreted, as susceptible, intermediate or resistant according to the Clinical Laboratory Standard Institute guidelines (CLSI, 2006). 


\section{Results and Discussion}

Staphylococcus aureus causes wide variety of diseases in humans and animals, ranging in severity from a mild skin infection to more severe diseases, such as pneumonia and septicaemia (Fagundas et al., 2010). Milk is an important vehicle for human infection of food borne pathogens, but the number of contamination is usually low and unnoticed. It is necessary to use selective enrichment media which allow the small number organisms to grow, that may otherwise be killed by the toxic effects of different enrichment media. Enrichment normally helps to multiply or resuscitate, that have been sub lethally damaged. In present study Staphyloccoccus broth was used to assist the selective isolation. Baired Parker agar used for the selective plating and typical black colonies surrounded by white halo were identified as a presumptive of $S$. aureus (Singh and Prakash, 2008).

Out of 100 samples 39 samples were showed presumptive results for Staphylococcus aureus isolates on Baired parker agar which further subjected for primary and secondary biochemical tests and confirmed as S. aureus (Colony morphology, Gram staining and biochemical tests). According to our study overall showed less prevalence than previous studies on cow milk conducted by Lingadurai and Velladurai $61 \%$ in Madurai in 2010 and by Sadashiv and Kaliwal $53.7 \%$ in North Karnataka in 2013. This variation in prevalence of Staphylococcus aureus in raw milk may be due to the number samples collected and methods used for isolation. In general goat milk has fewer tendencies to contaminate and handling also may not be very frequent as like cow milk this may also contribute to the overall prevalence in present study. Worldwide several studies suggest that $S$. aureus isolation rates in milk can vary from $13.5 \%$ to $64.7 \%$.
Among the 39 isolates, 21 was showed positive for tube coagulase test, it considered less than a study from Andhra Pradesh (Bharathy et al., 2015), who reported 65.5\% in a total of 40 samples. The differences in the results might be due sample size and types of sample included in the study. This all the positive isolates were induced hemolysis on 5\% sheep blood agar. This is agreed by (Teshome et al., 2016), who actually isolated the hemolysis induced colonies from raw milk samples in Ethiopia. This hemolysis property indicates the pathogenicity of the isolates.

DNA was extracted from all the presumptive positive isolates for Staphylococcus aureus by culture. PCR targeting mecA gene for Staphylococcus aureus was carried out and the results showed that out of 21/39 for mecA gene were positive. Out of the total 36 confirmed isolates, $6(16.6 \%)$ isolates were confirmed to be MRSA when subjected to PCR amplification using specific primers for mecA gene (Hamid et al., 2017). Presence of more isolates in the present study might be due to frequent use antibiotics in goats than other food animals. Our results also in accordance with the results of various authors who have also reported the presence MRSA by using PCR based mecA gene amplification which confirmed more than 99\% of MRSA isolates (Hata et al., 2010).

Among the 39 isolates of S. aureus, 32 isolates were produced biofilm colonies on congo red agar methods. Taj et al., (2012) assessed the clinical isolates of $S$. aureus for the production of biofilm using different methods. Out of $115 \mathrm{~S}$. aureus isolates, screening on Congo Red Agar showed biofilm formation in four $(3.47 \%)$ strains. The CRA method is fast, reproducible, and presents an advantage: the colonies remain viable in the medium for further analysis. Therefore the method was chosen in an attempt to improve its ability to identify 
biofilm production in Staphylococcus strains by making changes in the formula and adjusting different physical parameters. The method was easy to carry out and the results are usually based on the colony color produced, which ranges from red for non-bio film producing strains to black for biofilmproducing strains. Our results are in accordance with the results of (Arciola et al., 2002) who also contribute same advantages for this method.

MRSA strains are often resistant to antimicrobials other than beta lactams of which many members are widely used in both human and veterinary medicine ( Pinho et al., 2001). Studies show that susceptibility patterns of Staphylococcus aureus to antimicrobial agent have varied worldwide, but isolates were usually susceptible to Kanamycin, Ciprofloxacin, Vancomycin and Gentamicin (Alian et al., 2012; Daka and Yihdego, 2012).

Results of Table1 antibiotic susceptibility test against Staphylococcus aureus showed high resistance to Nalidixic acid(85\%) followed by Polymixin $\mathrm{B}(82.6 \%)$, Penicillin G(70.5\%). The high per cent of antimicrobial resistance exhibited to Nalidixic acid, Polymixin B and Penicillin G. In this study, line with the findings of who reported $87.2 \%$ resistance to Penicillin in Ethiopia, $64.3 \%$ of resistance to Penicillin G (Daka and Yihdego, 2012) in Hawassa area of Ethiopia and $80 \%$ resistance to penicillin which is reported in Sweden by Landin (2016) but in other hand it is in contrast to findings observed by Adesiyun (1994) who reported $23 \%$ of resistance to Penicillin G in West India and (Alian et al., 2012) who reported $17.4 \%$ of resistance to Penicillin G in Iran. Penicillin very commonly used antibiotics in ruminants this might be reason for the resistant isolates from goat milk. The probable explanation to the presence of antibiotic resistant is indiscriminate and repeated usage in animal and human health facilities. The present study has demonstrated the existence and alarming of Vancomycin resistance isolates and this put further threat to the public.

The antimicrobial susceptibility results in present study is contrast with the results (Alamin et al., 2013) obtained in where $S$. aureus isolates were found to be sensitive for the tested antibiotics in the following percentage: Amoxicillin (66.7\%), Gentamicin (88.8\%), Ciprofloxacin $(77.8 \%)$, Tetracycline (77.8\%). In the (Mekuria et al., 2013) study $S$. aureus isolates were sensitive to Vancomycin $(88.2 \%)$ and Trimethoprim-Sulfamethoxazole $(66.7 \%)$. In present study Vancomycin showed only $51.5 \%$ sensitivity against the isolates and indicates the increased prevalence of resistance. Tofaily et al., (2011) showed in their findings that $S$. aureus isolates were sensitive to Chloramphenicol (83.3\%), Doxycycline (100\%), Erythromycin (16.6\%) which has no similarity with the present study. Present isolates showed $71.55 \%$ sensitive to Erythromycin, which shows that not very frequent used in the treatment purpose in animals. In present study all the isolates were showed $72 \%, 83.2 \%$ and 76.3 $\%$ sensitivity to Cephalothin, Cefoxitin and Kanamycin compound which is agreed by (Teshmore et al., 2016), who also reported the maximum sensitivity in goat milk isolates.

In conclusion present study samples were collected from healthy goats and screened for the species specific $S$. aureus. Study clearly shows the presence of bacterial contamination and number of possible isolates also high compared to other findings on same research. Upon the characterization of $S$. aureus indicates the presence of pathogenicity by means of coagulase, hemolysis and biofilm positive isolates which represents the public health threat. Presence of MRSA produced isolates actually a matter of concern and it 
needs strict hygienic procedure during played a significant role in the emergence of handling, storage and transportation. resistance isolates.

Irrational use of antibiotics in animals has

Table.1 Antimicrobial susceptibility pattern of $S$. aureus isolated from goat milk samples

\begin{tabular}{|c|c|c|c|}
\hline Antibiotics & \% Resistance & $\%$ Intermediate & \% Sensitive \\
\hline Penicillin G(10 units) & 70.5 & 0 & 29.5 \\
\hline Amoxicillin(25 mcg) & 48.5 & 0 & 51.5 \\
\hline Cephalothin(30 mcg) & 20.8 & 7.2 & 72 \\
\hline Cefoxitin(30 mcg) & 10.5 & 6.3 & 83.2 \\
\hline Gentamicin(10 mcg) & 8.7 & 20.5 & 70.8 \\
\hline Kanamycin(30 mcg) & 15.5 & 8.2 & 76.3 \\
\hline Nalidixic acid(30 mcg) & 85.8 & 8.2 & 6 \\
\hline Ciprofloxacin(5 mcg) & 27.5 & 16.8 & 55.7 \\
\hline Norfloxacin(10 mcg) & 20.8 & 10.5 & 68.7 \\
\hline $\begin{array}{c}\text { Trimethoprime- } \\
\text { Sulfamethoxazole(25 } \\
\text { mcg) }\end{array}$ & 27.5 & 5.8 & 66.7 \\
\hline Polymixin B(300 units) & 82.6 & 0 & 17.4 \\
\hline Erythromycin(15 mcg) & 17.2 & 11.25 & 71.55 \\
\hline Vancomycin(30 mcg) & 36.7 & 11.8 & 51.5 \\
\hline $\begin{array}{c}\text { Chloramphenicol(30 } \\
\text { mcg) }\end{array}$ & 18.9 & 5.3 & 75.8 \\
\hline Doxycycline (30 mcg) & 20.5 & 15.8 & 63.7 \\
\hline Tetracyclin(30 mcg) & 42.8 & 10.8 & 46.4 \\
\hline
\end{tabular}


Table.2 Results for Primary Identification Tests

\begin{tabular}{|l|l|}
\hline \multicolumn{1}{|c|}{ Test Performed } & Results \\
\hline Gram Staining & Positive \\
\hline Coagulase & Positive \\
\hline Catalase & Positive \\
\hline Citrate & Positive \\
\hline Gas & Positive \\
\hline H2S & Positive \\
\hline Hemolysis & Positive \\
\hline Indole & Positive \\
\hline Motility & Positive \\
\hline Methyl Red & Positive \\
\hline Nitrate Reduction & Positive \\
\hline Oxidative Fermentative & Positive \\
\hline Oxidase & Positive \\
\hline Pigment & Positive \\
\hline Shape & Positive \\
\hline Urease & Positive \\
\hline Voges Proskauer & Positive \\
\hline
\end{tabular}

Table.3 Results for Secondary / Fermentation Tests

\begin{tabular}{|l|l|}
\hline \multicolumn{1}{|c|}{ Tests Performed } & Results \\
\hline Arabinose & Positive \\
\hline Cellobiose & Positive \\
\hline DNase & Positive \\
\hline Fructose & Positive \\
\hline Glucose & Positive \\
\hline Lactose & Positive \\
\hline Mannitol & Positive \\
\hline Mannose & Positive \\
\hline Raffinose & Positive \\
\hline Sucrose & Positive \\
\hline Trehalose & Positive \\
\hline Xylose & Positive \\
\hline
\end{tabular}


Fig.1 Prevalence of Staphylococcus aureus

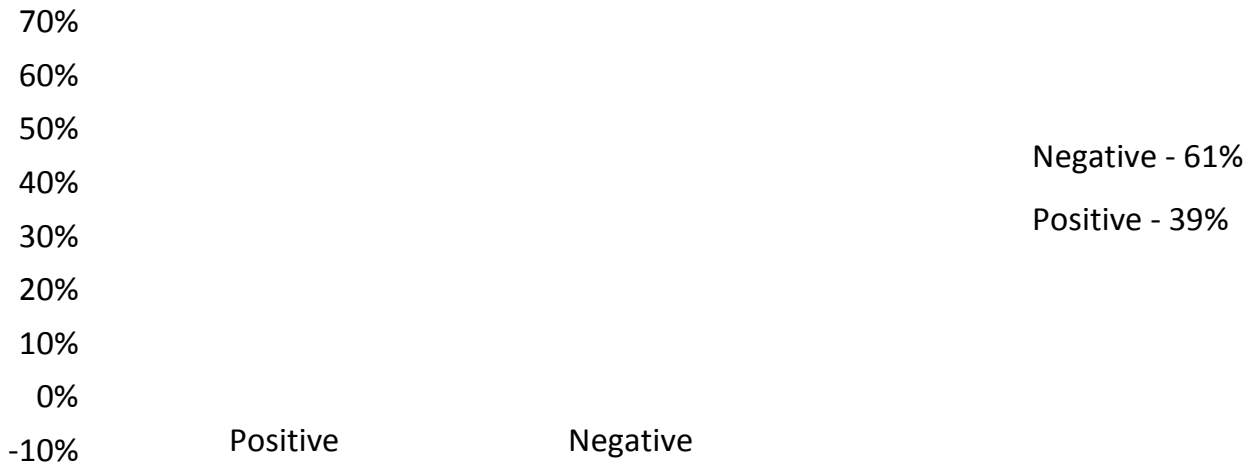

Fig.2 Prevalence of Coagulase positive and mecA gene isolates

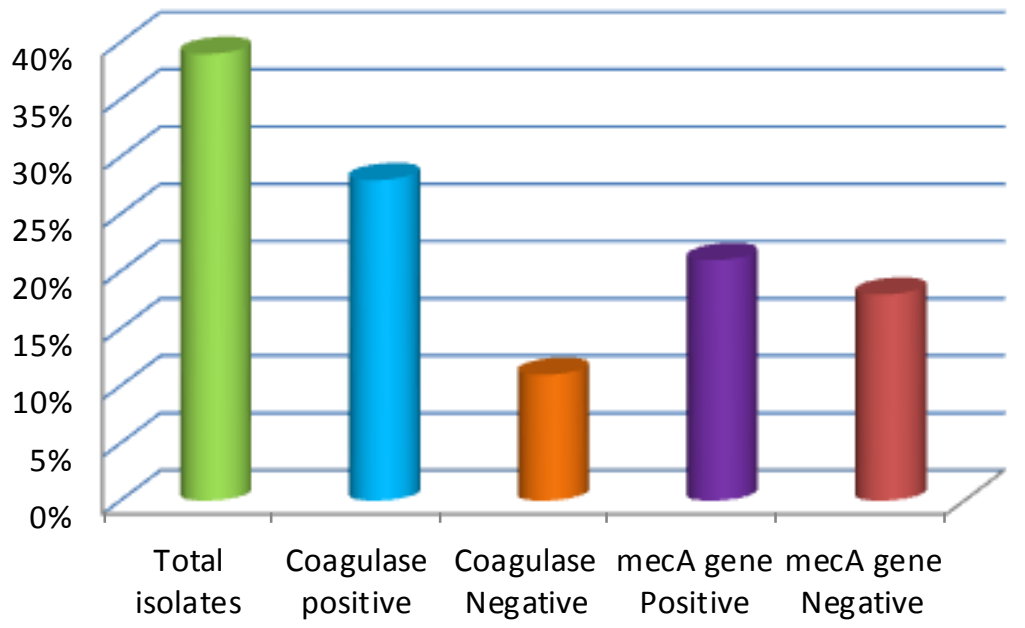

- Total isolates

- Coagulase positive

- Coagulase Negative

- mecA gene Positive

mecA gene Negative

Fig.3 Biofilm induced isolates

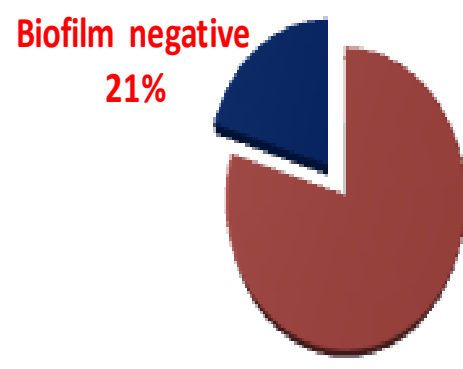

Biofim positive $79 \%$ 
Hence, there is an urgent need for more strict and hygienic preventive measures to reduce the $\mathrm{S}$. aureus contamination. The progressive increase in drug resistant isolates has revealed the need for the comprehensive and systematic integration of healthcare management systems. Further epidemiological studies need to be conducted to monitor the pathogens in order to get good correlation. Also, proper hygiene by both farmers and milk vendors suggested to follow at the time of handling, this will improve quality of health in society and reduce the cost of treatment and management of MRSA and emergence of Vancomycin resistant.

\section{References}

Alamin MA, Alqurashi AM, Elsheikh AS, Yasin TE (2013). Mastitis incidence and bacterial causative agents isolated from lactating camel (Camelus dromedaries). IOSR J. Afr. Vet. Sci. 2(3):07-10

Alférez, M. J. M., Barrionuevo, M., Aliaga, I. L., Sanz-Sampelayo, M. R., Lisbona, F., Robles, J. C., and Campos, M. S. (2001). Digestive utilization of goat and cow milk fat in malabsorption syndrome. Journal of Dairy Research. 68(3): 451-461.

Alian, F., Rahimi, E., Shakerian, A., Momtaz, H., Riahi, M., and Momeni, M. (2012). Antimicrobial resistance of Staphylococcus aureus isolated from bovine, sheep and goat raw milk. Global Veterinaria, 8(2): 111-114.

Arciola, C. R., Campoccia, D., and Montanaro, L. (2002). Detection of biofilm-forming strains of Staphylococcus epidermidis and S.aureus. Expert review of molecular diagnostics, 2(5): 478-484.

Bharathy, S., Gunaseelan, L., Porteen, K., and Bojiraj, M. (2015). Prevalence of Staphylococcus aureus in raw milk:
Can it be a potential public health threat. International Journal of Advanced Research, 3(2): 801-806.

Buehlmann, M., Frei, R., Fenner, L., Dangel, M., Fluckiger, U., and Widmer, A. F. (2008). Highly effective regimen for decolonization of methicillin-resistant Staphylococcus aureus carriers. Infection Control and Hospital Epidemiology, 29(6): 510-516.

Cui, L., Murakami, H., Kuwahara-Arai, K., Hanaki, H., and Hiramatsu, K. (2000). Contribution of a thickened cell wall and its glutamine nonamidated component to the vancomycin resistance expressed by Staphylococcus aureus $\mathrm{Mu} 50$. Antimicrobial agents and chemotherapy, 44(9): 2276-2285.

Daka, D. and Yihdego, D, 2012. Antibioticresistance Staphylococcus aureus isolated from cow's milk in the Hawassa area, South Ethiopia. Annals of Clinical Microbiology and Antimicrobials, 11(1): 26.

Di Ciccio, P., Vergara, A., Festino, A. R., Paludi, D., Zanardi, E., Ghidini, S., and Ianieri, A. (2015). Biofilm formation by Staphylococcus aureus on food contact surfaces: Relationship with temperature and cell surface hydrophobicity. Food Control, 50: 930-936.

Fagundes, H., Barchesi, L., Nader Filho, A., Ferreira, L. M., and Oliveira, C. A. F. (2010). Occurrence of Staphylococcus aureus in raw milk produced in dairy farms in Sao Paulo state, Brazil. Brazilian Journal of Microbiology, 41(2): 376-380.

Golding, G. R., Bryden, L., Levett, P. N., McDonald, R. R., Wong, A., Wylie, J., $\quad \ldots$ and Gravel, D. (2010). Livestock-associated methicillinresistant Staphylococcus aureus sequence type 398 in humans, Canada. 
Emerging infectious diseases. 16(4):587.

Hamid, S., Bhat, M. A., Mir, I. A., Taku, A., Badroo, G. A., Nazki, S., and Malik, A. (2017). Phenotypic and genotypic characterization of methicillinresistant Staphylococcus aureus from bovine mastitis. Veterinary world, 10(3): 363.

Harrison, E. M., Weinert, L. A., Holden, M. T., Welch, J. J., Wilson, K., Morgan, F. J., ... and Paterson, G. K. (2014). A shared population of epidemic methicillin-resistant Staphylococcus aureus 15 circulates in humans and companion animals. MBio, 5(3).

Hata, E., Katsuda, K., Kobayashi, H., Uchida, I., Tanaka, K. and Eguchi, M. (2010) Genetic variation among Staphylococcus aureus strains from bovine milk and their relevance to methicillin-resistant isolates from humans. Microbiology., 48(6): 21302139

Jyothi, J. S., Putty, K., Reddy, Y. N., Dhanalakshmi, K., and Umair, M. H. (2018). Antagonistic effect of ursolic acid on Staphylococcal biofilms. Veterinary World, 11(10):1440.

Kumar, R., Yadav, B. R., and Singh, R. S. (2010). Genetic determinants of antibiotic resistance in Staphylococcus aureus isolates from milk of mastitic crossbred cattle. Current Microbiology, 60(5): 379-386.

Landin H (2006). Treatment of mastitis in Swedish dairy production (in Swedish with English summary). Svensk Veterinartidning 58:19-25.

Loncaric, I., Kübber-Heiss, A., Posautz, A., Stalder, G. L., Hoffmann, D., Rosengarten, R., and Walzer, C. (2013). Characterization of methicillin-resistant Staphylococcus spp. carrying the mecC gene, isolated from wildlife. Journal of
Antimicrobial Chemotherapy, 68(10): 2222-2225.

Mekuria A, Asrat D, Woldeamanuel Y, and Tefera G (2013). Identification and antimicrobial susceptibility of Staphylococcus aureus isolated from milk samples of dairy cows and nasal swabs of farm workers in selected dairy farms around Addis Ababa, Ethiopia. Afr. J. Microbiol. Res. 7(27): 3501-3510.

Mirani, Z. A., Aziz, M., Khan, M. N., Lal, I., ul Hassan, N., and Khan, S. I. (2013). Biofilm formation and dispersal of Staphylococcus aureus under the influence of oxacillin. Microbial pathogenesis, 61: 66-72.

Navratna, V., Nadig, S., Sood, V., Prasad, K., Arakere, G., and Gopal, B. (2010). Molecular basis for the role of Staphylococcus aureus Penicillin binding protein 4 in antimicrobial resistance. Journal of bacteriology, 192(1): 134-144.

Phillips, I. (1993). Cowan and Steel's manual for the identification of medical bacteria. Journal of Clinical Pathology, 46(10): 975.

Pinho, M. G., de Lencastre, H., and Tomasz, A. (2001). An acquired and a native penicillin-binding protein cooperate in building the cell wall of drug-resistant staphylococci. Proceedings of the National Academy of Sciences, 98(19): 10886-10891.

Singh, P., and Prakash, A. (2008). Isolation of Escherichia coli, Staphylococcus aureus and Listeria monocytogenes from milk products sold under market conditions at Agra region. Acta agriculturae Slovenica, 92(1): 83-88.

Skockova, B. J. L. N. A., and Janstova, B. (2014). in model samples of milk and fresh cheese. Journal of Food and Nutrition Research, 53(4): 389-392.

Stenhem, M., ortqvist, A., Ringberg, H., 
Larsson, L., Olsson-Liljequist, B., Hæggman, S., and Ekdahl, K. (2010). Imported methicillin-resistant Staphylococcus aureus, Sweden. Emerging infectious diseases, 16(2): 189.

Taj, Y., Essa, F., Aziz, F., and Kazmi, S. U. (2012). Study on biofilm-forming properties of clinical isolates of Staphylococcus aureus. The Journal of Infection in Developing Countries, 6(05): 403-409.

Teshome, B., Tefera, G., Belete, B., and Mekuria, A. (2016). Prevalence and antimicrobial susceptibility pattern of Staphylococcus aureus from raw camel and goat milk from Somali region of Ethiopia. African Journal of
Microbiology Research, 10(28): 10661071.

Tofaily YI, Kh AL-M, Alrodhan AN (2011). Study on Clinical Mastitis (Bacteriological) in She-Camels (Camelus dromedarius) in Some Areas of Middle Euphrates in Iraq. J. Vet. Med. Sci. 10: 2.

Trncikova, T., Piskernik, S., Kaclikova, E., Mozina, S. S., Kuchta, T., and Jersek, B. (2010). Characterization of Staphylococcus aureus strains isolated from food produced in Slovakia and Slovenia with regard to the presence of genes encoding for enterotoxins. Journal of Food and Nutrition Research, 49(4): 215-220.

\section{How to cite this article:}

Kiruthiga, R., S. Leonal Rabins and Vinoth Kumar G.D. 2020. Screening and Characterization Staphylococcus aureus from Goat Milk. Int.J.Curr.Microbiol.App.Sci. 9(08): 212-222. doi: https://doi.org/10.20546/ijcmas.2020.908.024 